\title{
Study on the Therapeutic Effect of ESPB for Patients Undergoing Percutaneous Vertebroplasty
}

\section{Peng Ju (D 18996522966@189.cn )}

Department of Orthopedic, The Third Affiliated Hospital of Chongqing Medical University

\section{Dianming Jiang}

Department of Orthopedic, The Third Affiliated Hospital of Chongqing Medical University

\section{Research Article}

Keywords: osteoporotic vertebral compression fracture (OVCF), percutaneous vertebroplasty (PVP), erector spinae plane block (ESPB)

Posted Date: February 10th, 2022

DOI: https://doi.org/10.21203/rs.3.rs-1332284/v1

License: (1) This work is licensed under a Creative Commons Attribution 4.0 International License. Read Full License 


\section{Abstract}

Objective To compare the difference oftherapeutic effect between percutaneous vertebroplasty (PVP)alone and PVP + Erector spinal plane block (ESPB) in the treatment of osteoporotic vertebral compression fracture (OVCF).

Methods After admission, 100 patients with osteoporotic vertebral compression fracture were randomly divided into PVP group (control group) and PVP+ESPB group (observation group) by lottery with 50 patients in each group.The visual analog pain scores (VAS) and oswestry disability index (ODI) of each group were compared before surgery, 2 hours after surgery and at the time of hospital discharge. The operation time, filling volume of intraoperative bone cement, intraoperative bloodloss, and surgery cost of each group were compared.Theearly postoperative ambulation time and early postoperative defecation (stool) time ofeach group were compared to explore the difference.

Results The PVP+ESPB group had better visual analog pain scores (VAS) and oswestry disability index (ODI) at 2 hours after surgery and at the time of hospital discharge, and better early postoperative ambulation timeand early postoperative defecation (stool) timethan the PVP group $(p<0.05)$. There were no differences in the visual analog pain scoresand oswestry disability index before surgery, operative time, filling volume of intraoperative bone cement, intraoperative blood loss, and surgery cost between the two groups, and no complications occurred between the two groups after surgery and at the time of hospital discharge.

Conclusion PVP+ESPB for OVCF is associated with lower VAS, more significant pain relief, and lower oswestry disability index in patients after surgery than PVP alone for OVCF, and patients are able to engage in ambulation time earlier. Meanwhile, PVP+ESPB promotes recovery of intestinalfunction and improves patients' quality of life so as tocontribute toquick recovery.

\section{Introduction}

Due to the social aging, the incident rate of osteoporotic vertebral compression fracture has increased year by year with its insidious onset and low consultation rate seriously threatening the health of the elderly, which is more significant in postmenopausal women [1-3]. In view of the actual clinical problems, researches on OVCF have become urgent and necessary [4, 5]. Patients with osteoporotic vertebral compression fractures mainly feature low back pain and aggravated postural changes with spinal deformation, decreased cardiopulmonary function and gastrointestinal instabilityin severe cases, and even spinal nerve compression leading to paralysis and life-threatening conditions[6]. For patients with OVCF, spine surgeons now often depend on PVP which relieves the patients' pain but often results in myalgic pain in the back far from the diseased vertebrae[7]. Erectal spinal plane block involves the local injection of anesthetic drugs into the deep surface of the erector spinae and the transverse process clearance (at the root above the transverse process) under ultrasound guidance or G-arm X-ray machine positioning, which spreads into the paravertebral space and blocks the posterior spinal nerve branches 
and possibly the anterior spinal nerve branches and the communicating branches[8]. In order to improve the distal involvement pain of the diseased spine and to promote the early functional exercise of patients, we consider to perform an adjuvant erector spinae plane block in patients with PVP. ESPB mainly blocks the posterior branch of the spinal nerve which primarily innervates the corresponding segment of the erector spinae muscle, and the residual myalgic pain after PVP can be relievedwhen it is blocked, improving the postoperative pain of patients and thus promoting the patients' quick recovery $[9,10]$. The author performed anatomical localization of two formalin-soaked cadavers at Chongqing Three Gorges Medical College in April 2021 to study the posterior spinal nerve branch course innervating the erector spinae muscle. One hundred patients with osteoporotic vertebral compression fractures collected from July 2021 to December 2021 at Chongqing University Three Gorges Hospitalwere studied in randomized groups, and the results are reported as follows.

\section{Application Anatomy}

The erector spinae muscle, also known as the sacrospinalis, is located longitudinally on the posterior back of the trunk and in the sulcus on both sides of the spine, which starts from the back of the sacrum and the posterior part of the iliac crest, fall upward into three groups of muscle bundles, and ends at the vertebrae and ribs along the way which are innervated by[11] the posterior branch of the spinal nerve. The posterior branch of the spinal nerve is mixed and thin, which generally travels posteriorly around the lateral aspect of the superior articular process to the adjacent transverse process and then falls into medial and lateral branches[12] except for the sacral nerve. Located in the epicondyles, articular surfaces, and intervertebral ligaments of the spine, the medial branch innervatesthe erector spinae, multifidus, and piriformis of the spinal muscles. The lateral branch mainly innervates the longest muscle of the erector spinae and the iliopsoas muscle[13].

As shown in Figure 2, an autopsy was performed in April 2021to actually locate the posterior spinal nerve branch courseat Chongqing Three Gorges Medical College.

\section{Cases And Experimental Methods}

One hundred cases of osteoporotic vertebral compression fractures were collected from July 2021 to December 2021 in Chongqing University Three Gorges Hospital aged 60-90 years with 83 female patients and 17 male patients, which have been reviewed by the hospital ethics committee. Inclusion criteria: 1 . age greater than or equal to 60 years; 2 . no history of violent trauma,MRI suggesting fresh spine fracture (T2 image of high signal and T1 image of low signal), and no occupying compression of the spinal canal; 3 . bone density test (dual-energy photon assay) suggesting bone density $\leq-2.5 \mathrm{SD}$; 4 . diseased vertebral segments are 1-2 segments, and the diseased vertebral range is T5-L5. Exclusion criteria: 1. spinal tumor pathological fracture; 2 . the patientsare unconscious and unable to communicate accurately; 3 . the diseased vertebrae are greater than ( $>) 2$ segments. Cases admitted to the hospital that were eligible for the study were randomly divided into observation and control groups by lottery. 


\section{Study methods}

The study was carried out after the patients signed the informed consent. PVP +ESPB observation group The PVP procedure was performed firstly with patients placed in prone position. The diseased vertebra was located through G-arm X-ray machine positioning so that the bilateral needle entry points were determined.Routine disinfection and draping were conducted.The local anesthesia was completed with $2 \%$ lidocaine at the puncture point, and a $1 \mathrm{~cm}$ incision was made at the puncture point with a sharp blade.The puncture needle was placed and the position of the puncture needle was adjusted. The fluoroscopy showed that the tip of needlewas located at the posterior edge of the vertebral body in the side position and orthotropically located at the inner edge of the root shadow of the arch. The puncture needle cannula was removed and the working cannula was placed along the guide needle. The fluoroscopyfound that the tip of the drill reached the anterior middle $1 / 3$ of the vertebral body.The drill was removed to mix the bone cement (polymethylmethacrylate). When the bone cement was in the state of toothpaste, the appropriate amount of bone cement was filled with the assistance of the working cannula. ESPB treatment was then performed, which meant that $5 \mathrm{ml}$ of ropivacaine $(0.75 \%$, Nelapine) was given to block the posterior branch of the spinal nerve at the root above the transverse process bilaterally in the diseased vertebrae with the assistance of the G-arm. The incision was disinfected locally, a dressing was applied to cover the incision, and the patients returned to the ward after surgery.

PVP control group Conventional PVP surgical treatment was completed for the diseased vertebrae.

\section{Records and related scores}

Evaluate the visual analog pain scoreand oswestry disability index before surgery, 2 hours after surgery, and at hospital discharge for each group; record the operation time, filling volume of intraoperative bone cement, intraoperative bloodloss, surgery cost, and the presence of postoperative complications for each group; record the early postoperative ambulation time and early postoperative defecation (bowel movement) time for each group.

\section{Statistical analysis}

The data were statistically analyzed through SPSS 25.0 software. T-test analysis was performed for the measurement data between the two groups, and $p<0.05$ represented statistical differences.

\section{Study Results}

A total of 100 patients with OVCF were collected in the trial, with 50 in the PVP+ESPB observation group and 50 in the PVP control group. The surgery was successful in both groupswithout cases of death or disability, and there were no postoperative complications in either group after surgery. There were no statistical differences between the observation group and the control group in the preoperative VAS and 
ODI scores. There were statistical differences between the two groups in the VAS and ODI scores at 2 hours after surgery and at hospital discharge. There were statistical differences between the two groups in theearly postoperative ambulation time and early postoperative defecation (stool) time. There were no statistical differences between the two groups in terms of the operation time, filling volume of intraoperative bone cement, intraoperative bloodloss, and surgery cost. The specific results are shown in the following tables.

Common case The female patient Yi of 82 years old was admitted to the hospital with low back pain for 2 days. Physical examination: lumbar 1 vertebral spine percussion pain, lumbosacral pressure pain; no abnormal sensation in both lower limbs, grade 5 muscle strength of both lower limbs. MRI examination of lumbar spine suggested: fresh fracture of lumbar 1 vertebra. Preoperative diagnosis: compression fracture of lumbar 1 vertebra; severe osteoporosis. With the assistance of G-arm X-ray machine, the lumbar 1 vertebral body and bilateral puncture points were positioned, and the working cannula was placed along the guide needleafter satisfactory puncture.The bone cement was mixed, and the diseased vertebra was filled with bone cementafter the bone cement was in the state of toothpaste. ESPB treatment was performed by injecting $5 \mathrm{ml}$ of ropivacaine respectivelyat the root above the lumbar 1 transverse processes bilaterally with the assistance of G-arm. (Figure 3 - Figure 8 )

The patient's operative time was 53 minuteswith intraoperative blood loss of $2 \mathrm{ml}$. The patient had the VAS of 8 and ODI of $80 \%$ before surgery,VAS score of 1 and ODI index of $24 \% 2$ hours after surgery, and VAS of 1 andODI of $10 \%$ at hospital discharge. The patient returned to the ward and engage in the ambulation time after surgery.

\section{Discussion}

In today's aging society, osteoporotic vertebral compression fractures has become more common in clinical practice[14, 15]. OVCF refers to spinal fractures that occur with or without minor trauma due to decreased bone density and bone mass caused by osteoporosis as well as decreased bone strength, mainly manifesting as pain and limited movement in the chest, waist and back with or without neurological symptoms in the lower extremities[16]. OVCF has an insidious onset with an increasing incidence rate year by year, whichseriously affects the elderly and especially postmenopausal women. $83 \%$ of the 100 patients in this study were women, accounting for the vast majority[17]. The pain caused by OVCF seriously affects the quality of life, range of activity, and psychological mood of patients, while long-term bed rest could further lead to complications such as deep vein thrombosis in the lower extremities, pressure sores, and pulmonary infections, and may even endanger life[18]. According to the relevant literature, the mortality rate of patients with OVCF for one year is significantly higher than that of the general population[19].

The primary surgical treatment means for OVCF is percutaneous vertebroplasty and percutaneous kyphoplasty (PKP)[20]. Vertebroplasty can enhance the stability and strength of the diseased vertebrae, while the high temperature of bone cement can inactivate the inflammatory factors in the vertebral body 
and reduce the nociceptive sensitivity of the spinal branches, so that the pain symptoms of patients can be improved after surgery[21]. However, it is found that patients often have residual postoperative myalgic pain distributed along the erector spinae muscle, which even manifests distal pain radiation. According to the anatomy, the erector spinae muscle is innervated by the posterior branch of the spinal nerve which emanates posteriorly to the intervertebral foramen and travels distally for at least 3 vertebral segments except for the sacral nerve. It is not difficult to explain why patients with OVCF often have a combination of myalgic pain distal to the diseased vertebrae. In this study, local anesthetic ropivacaine was injected into the deep surface of the erector spinae and the transverse process (root above the transverse process) under G-arm X-ray machine positioning, which diffused into the paravertebral space and blocked the posterior branch of the spinal nerve, thus blocking the erector spinae and improving the patients' myalgic pain[22, 23]. Certainly, according to the anatomy, the posterior branch of the spinal nerve blocked at the level of the diseased vertebra is actually the posterior branch of the spinal nerve that emanates downward from the level of the previous vertebra. However, this superior posterior branch of the spinal nerve is the one that primarily innervates the level of the diseased vertebra, hencethe block is consideredat the root above the transverse process of the diseased vertebra.

The drug for ESPB treatment is ropivacaine with the trade name of Nelapine, which is manufactured in 10 $\mathrm{ml}: 75 \mathrm{mg}$ and concentration $0.75 \%$ by AstraZeneca $A B$. It is suitable for mixed nerves such as the posterior branch of the spinal nerve because of its high lipid solubility and anesthetic efficacy, as well as its strong separation effect on motor nerve block and sensory nerve block. Ropivacaine is also less toxic to the heart, so it is available for local blocks in elderly patients[24, 25]. The commonly used concentration of this drug is between $0.5 \%$ and $1.0 \%$ and the blockade of sensory nerves is about 3-5 hours, so that it is fast and long lasting in local analgesia. The maximum amount of the drug is $200 \mathrm{mg}$, namely $40 \mathrm{ml}$. The patients included in the trial were controlled to have no more than 2 spinal segments. For patients with 2 segments, $5 \mathrm{ml}$ of ropivacaine was given to each side of the diseased vertebra, and the total amount was $20 \mathrm{ml}$, so it was safe and reliable.

There were no statistical differences in the preoperative VAS and ODI scores between the PVP+ESPB observation group and PVP control group, indicating that there were no significant differences in the condition of patients admitted to the hospital between the two groups. However, in the comparison of VAS and ODI scores at 2 hours after surgery and at hospital discharge, the observation group had lower scores than the control group which represented statistical differences, indicating that the patients in the observation group had better pain relief and more obvious improvement in lumbar activities after ESBP treatment, and ESPB had a significant effect of relieving erector spinae pain. According to the test results, there were statistical differences between the observation group and the control group in the early postoperative ambulation time and the early postoperative defecation (stool) time. It indicates that the patients in the observation group improved their pain symptoms earlier and faster with ESPB-assisted treatment, and patients were more active in early postoperative ambulation, promotion of bowel movement, and early postoperative defecation (stool), thus promoting early and rapid recovery of OVCF patients. According to the study results, there was no statistical difference between the two groups in terms of operative time, intraoperative bone cement filling volume, intraoperative blood loss, and surgery 
cost, etc. ESPB treatment was less invasive, and did not increase surgery time, intraoperative blood loss or surgery cost of patients when taking the control group into consideration. There was no statistical difference in the amount of intraoperative bone cement filling between the two groups, and no postoperative complications occurred in either group after surgery. According to the above results, ESPB did not increase the surgery time,operative risk or the financial burden of patients when compared with PVP, but diffuses the local anesthetic drug ropivacaine into the paravertebral space, blocks the posterior branch of the spinal nerve, further relieves the residual myalgic pain of OVCF patients and improves their pain symptoms, thus promoting their rapid recovery.

ESPB treatment was reported by Ferero et al.[22] in 2016 and first applied in the analgesic treatment of thoracic neuropathic pain.ESPB is a newest technique of trunk nerve block with low risk, small trauma, and significant effect, which has been used in perioperative analgesia for thoracic surgery, breast surgery, and abdominal surgery. However, the application of ESPB in spine surgery is less reported.But with its advantages, it is believed that in the near future ESPB will be widely used not only in OVCF patients but also in other areas of spine surgery[26, 27]. In terms of the treatment of chronic pain in the chest, waist and back, for example, there are many patients with chronic pain in the chest, waist and backyetimageological examination often indicates no significant abnormalities in the chest, waist and back. The tension in the erector spinae muscle is found through physical examination with pain appearing under pressure. Recent studies have demonstrated that the posterior branch of the spinal nerve plays an important role in chronic pain of spinal origin[28], and ESPB directly blocks the posterior branch of the spinal nerve, thereby relieving the tension in the erector spinae muscle and relieving pain in the chest, waist and back. In terms of routine perioperative analgesia in spine surgery, lumbar spondylolisthesis, lumbar disc herniation, lumbar spinal stenosis, and thoracolumbar fractures are common in spine surgery and often require surgical treatment. Spine surgery is invasive and prolonged with more pronouncedpostoperative pain than general surgery. Deng Lin et al.[29] have reported that for posterior lumbar surgery in spine surgery, the ultrasound-guided vertical spinal muscle block was performed in the T7 plane as an adjunct to general anesthesia. This report suggests that ESPB can provide postoperative analgesia, reduce the dosage of analgesic pump drugs and additional analgesics, and improve patient satisfaction with the postoperative analgesic effect. In the adjuvant treatment of patients with spinal tumors, the incidence of primary spinal tumors is low while metastatic spinal tumors account for more than $95 \%$ of cases, often involving the thoracic (70\%) and lumbar spine(20\%)[30]. Spinal tumors often have insidious onset, among which the primary lesion of spinal metastases are mostly breast cancer, prostate cancer, lung cancer, kidney cancer and thyroid cancer[31]. Ueshima et al. [32] performed ESPB in a patient with T8 tumor resection, and the sensory block plane was ideal to provide adequate analgesia for the patient. In terms of clinical treatment, when patients are found to have metastatic spinal tumors, their diseasesare often at an advanced stage. Patients are not strongly willing to accept spinal surgery and often choose radiotherapy and interventional therapy. However, for patients with metastatic spinal tumors, the cancer pain in the thoracolumbar back is often unresolved. With the advantages of local medication, low trauma and significant analgesic effect, ESPB can reduce cancer pain for patients with spinal tumors, especially those with metastatic spinal tumors. In terms of adjuvant 
anesthetic analgesia for patients who cannot tolerate general anesthesia for spinal incision infection, spinal surgery often features large wound surface, deep incision and long time with implants, and the risk of incisional infection is higher. Liu TZ et al. reported a case of vertical spinal plane block used for lumbar incisional debridement[33] in a 75-year-old male patient who developed postoperative incisional infection. Considering the patient's advanced age, obesity and long history of heavy smoking, a second general anesthesia in a short period of time may increase the incidence of perioperative anesthesia-related complications. Liu TZ et al. used ESPB for the first time in this patient to avoid the complications that may result from general anesthesia, and the operator successfully performed incisional debridement and achieved intraoperative and postoperative analgesia.

As a new nerve block technique, ESPBhas a superficial point of action and is far from important organs and blood vessels, contributing to a low risk of complications such as pneumothorax, hematoma, and nerve injury. ESPB has the advantages of high safety, simple operation, less toxic and side effects through localization and local application. ESPB not only has a significant adjunctive analgesic effect in patients undergoing percutaneous vertebroplasty, but also will exert a positively therapeuticeffect in other areas of spinal surgery.

\section{Declarations}

\section{Author contributions}

Peng Ju: Application of statistical, mathematical, computational, or other formal techniques to analyze or synthesize study data. Dianming Jiang: Supervision, Study guide. Statement: All authors have read and approved the final submitted manuscript.

\section{Acknowledgements}

The author would like to thank all doctors and nurses in the orthopedic department from the Chongqing University Three Gorges Hosptial for their contributions to this study.

\section{Availability of data and materials}

All the data will be available upon motivated request to the corresponding author of the present paper.

\section{Conflicts of interest}

None of the authors have any conflicts of interest regarding the material presented in this submission.

\section{Ethics statement}


All of the studies discussed in this submission were approved by Institutional Review Board (IRB) of The Chongqing University Three Gorges Hosptial.

\section{References}

1. Expert consensus on the diagnosis and treatment of osteoporotic vertebral compression fractures, 2021 edition. Chin Medl J. 2021;101(41):3345-53.

2. Long Y, Yi W, Yang D. Advances in Vertebral Augmentation Systems for Osteoporotic Vertebral Compression Fractures. Pain Res Manag. 2020;2020:3947368.https://doi.org/10.1155/2020/3947368.

3. Xiao W, He J, Fu W, Xu Y, Zhang Z. LOX gene polymorphisms are associated with osteoporotic vertebral compression fracture in postmenopausal Chinese women. Gene. 2020;741:144543.https://doi.org/10.1016/j.gene.2020.144543.

4. Li HM, Zhang RJ, Gao H, et al. New vertebral fractures after osteoporotic vertebral compression fracture between balloon kyphoplasty and nonsurgical treatment PRISMA. Medicine (Baltimore). 2018;97(40):e12666.https://doi.org/10.1097/md.0000000000012666.

5. Jackson A, Wasfie T, Brock C, et al. Fragility Vertebral Compression Fractures in Postmenopausal Women: The Role of a Fracture Liaison Service Program. Am Surg. 2020;86(12):16369.https://doi.org/10.1177/0003134820933254.

6. Chen Z, Lou C, Yu W, He D. Comparison of Intravertebral Clefts between Kümmell Disease and Acute Osteoporotic Vertebral Compression Fracture: A Radiological Study. Orthop Surg. 2021;13(7):197986.https://doi.org/10.1111/os.13025.

7. Lu L, Liu Y, Nazierhan S, et al. Expression changes of IL-17 in zoledronic acid combined with PVP technology in the treatment of postmenopausal osteoporotic vertebral compression fracture and its predictive value of relapse. J Musculoskelet Neuronal Interact. 2020;20(4):563-9.

8. Kot P, Rodriguez P, Granell M, et al. The erector spinae plane block: a narrative review. Korean $\mathrm{J}$ Anesthesiol. 2019;72(3):209-20.https://doi.org/10.4097/kja.d.19.00012.

9. Qiu Y, Zhang TJ, Hua Z. Erector Spinae Plane Block for Lumbar Spinal Surgery: A Systematic Review. J Pain Res. 2020;13:1611-9.https://doi.org/10.2147/jpr.S256205.

10. Altıparmak B, Korkmaz Toker M, Uysal A, Turan M, Gümüş Demirbilek S. Comparison of the effects of modified pectoral nerve block and erector spinae plane block on postoperative opioid consumption and pain scores of patients after radical mastectomy surgery: A prospective, randomized, controlled trial. J Clin Anesth. 2019;54:61-5.https://doi.org/10.1016/j.jclinane.2018.10.040.

11. Liu ZY. Systematic Anatomy, 6th Edition: 6th Edition. People's Medical Publishing House, 2003.

12. Liu ZY. Systematic Anatomy: 6th Edition. People's Medical Publishing House; 2003.

13. Mayer HM. Minimally Invasive Spine Surgery, 2nd Edition. People's Medical Publishing House, 2006. p. 26. 
14. Chen J, Xu C, Yu J. Vesselplasty for the treatment of osteoporotic vertebral compression fractures with peripheral wall damage: a retrospective study. Br J Neurosurg. 2020:1-

11.https://doi.org/10.1080/02688697.2020.1862054.

15. Sun Y, Ma H, Yang F, Tang X, Yi P, Tan M. Clinical Efficacy and Safety of Zoledronic Acid Combined with PVP/PKP in the Treatment of Osteoporotic Vertebral Compression Fracture: A Systematic Review and Meta-Analysis of Randomized Controlled Trials. Biomed Res Int. 2021;2021:6650358.https://doi.org/10.1155/2021/6650358.

16. Jin YZ, Lee JH, Xu B, Cho M. Effect of medications on prevention of secondary osteoporotic vertebral compression fracture, non-vertebral fracture, and discontinuation due to adverse events: a metaanalysis of randomized controlled trials. BMC Musculoskelet Disord. 2019;20(1):399.https://doi.org/10.1186/s12891-019-2769-8.

17. Eguchi $Y$, Toyoguchi T, Orita S, et al. Reduced leg muscle mass and lower grip strength in women are associated with osteoporotic vertebral compression fractures. Arch Osteoporos. 2019;14(1):112.https://doi.org/10.1007/s11657-019-0668-0.

18. Zhao P, Guo A, Tan Z, et al. The evaluation of the treatment for old osteoporotic vertebral compression fracture pain by percutaneous vertebroplasty. Medicine (Baltimore). 2020;99(27):e20479.https://doi.org/10.1097/md.0000000000020479.

19. Wang $\mathrm{O}$, Hu Y, Gong S, et al. A survey of outcomes and management of patients post fragility fractures in China. Osteoporos Int. 2015;26(11):2631-40.https://doi.org/10.1007/s00198-015-3162-6.

20. Wang B, Zhao CP, Song LX, Zhu L. Balloon kyphoplasty versus percutaneous vertebroplasty for osteoporotic vertebral compression fracture: a meta-analysis and systematic review. J Orthop Surg Res. 2018;13(1):264.https://doi.org/10.1186/s13018-018-0952-5.

21. Buchbinder R, Johnston RV, Rischin KJ, et al. Percutaneous vertebroplasty for osteoporotic vertebral compression fracture. Cochrane Database Syst Rev. 2018;4(4):Cd006349.https://doi.org/10.1002/14651858.CD006349.pub3.

22. Forero M, Adhikary SD, Lopez H, Tsui C, Chin KJ. The Erector Spinae Plane Block: A Novel Analgesic Technique in Thoracic Neuropathic Pain. Reg Anesth Pain Med. 2016;41(5):6217.https://doi.org/10.1097/aap.0000000000000451.

23. Forero M, Rajarathinam M, Adhikary S, Chin KJ. Continuous Erector Spinae Plane Block for Rescue Analgesia in Thoracotomy After Epidural Failure: A Case Report. A A Case Rep. 2017;8(10):2546.https://doi.org/10.1213/xaa.0000000000000478.

24. Wang W, Zhu M, Xu Z, et al. Ropivacaine promotes apoptosis of hepatocellular carcinoma cells through damaging mitochondria and activating caspase-3 activity. Biol Res. 2019;52(1):36.https://doi.org/10.1186/s40659-019-0242-7.

25. Fudim M, Boortz-Marx RL, Ganesh A, et al. Splanchnic Nerve Block for Chronic Heart Failure. JACC Heart Fail. 2020;8(9):742-52.https://doi.org/10.1016/j.jchf.2020.04.010.

26. Singh S, Choudhary NK, Lalin D, Verma VK. Bilateral Ultrasound-guided Erector Spinae Plane Block for Postoperative Analgesia in Lumbar Spine Surgery: A Randomized Control Trial. J Neurosurg 
Anesthesiol. 2020;32(4):330-4.https://doi.org/10.1097/ana.0000000000000603.

27. Oh SK, Lim BG, Won YJ, Lee DK, Kim SS. Analgesic efficacy of erector spinae plane block in lumbar spine surgery: A systematic review and meta-analysis. J Clin Anesth.

2022;78:110647.https://doi.org/10.1016/j.jclinane.2022.110647.

28. Manchikanti L, Pampati V, Falco FJ, Hirsch JA. Growth of spinal interventional pain management techniques: analysis of utilization trends and Medicare expenditures 2000 to 2008. Spine (Phila Pa 1976). 2013;38(2):157-68.https://doi.org/10.1097/BRS.0b013e318267f463.

29. Deng L, Xie C, Deng T, Liang L. Clinical observation of ultrasound-guided erector spinae plane block used in posterior lumbar spine surgery. J Mod Med Health. 2018;34(22):34313433.https://doi.org/10.3969/j.issn.1009-5519.2018.22.003.

30. Choi D, Bilsky M, Fehlings M, Fisher C, Gokaslan Z. Spine Oncology-Metastatic Spine Tumors. Neurosurgery. 2017;80(3s):S131-s7.https://doi.org/10.1093/neuros/nyw084.

31. Constans JP, de Divitiis E, Donzelli R, Spaziante R, Meder JF, Haye C. Spinal metastases with neurological manifestations. Review of 600 cases. J Neurosurg. 1983;59(1):1118.https://doi.org/10.3171/jns.1983.59.1.0111.

32. Ueshima H, Otake H. WITHDRAWN: Clinical experiences of ultrasound-guided erector spinae plane block for thoracic vertebra surgery. J Clin Anesth.

2017;38:137.https://doi.org/10.1016/j.jclinane.2016.12.028.

33. Liu TZ, Hua L, Wan L. A case of erector spinae plane block for lumbar spine incisional debridement. J Clin Anesth. 2018;34(9):933-4.https://doi.org/10.12089/jca.2018.09.029.

\section{Tables}

Table

Results Comparison table between clinical control group and sbservation group

\begin{tabular}{|lllll|}
\hline Indicators & \multicolumn{2}{l}{ Subgroups (mean \pm standard deviation) } & & T \\
\cline { 2 - 5 } & $\begin{array}{l}\text { Control group } \\
(\mathrm{n}=50)\end{array}$ & $\begin{array}{l}\text { Observation group } \\
(\mathrm{n}=50)\end{array}$ & & \\
\hline Preoperative VAS (score) & $7.88 \pm 0.69$ & $7.96 \pm 0.70$ & -0.576 & 0.566 \\
\hline $\begin{array}{l}\text { VAS 2 hours after } \\
\text { surgery(score) }\end{array}$ & $2.78 \pm 0.74$ & $1.32 \pm 0.51$ & 11.504 & $0.000^{\star \star}$ \\
$\begin{array}{l}\text { VAS at hospital } \\
\text { discharge (score) }\end{array}$ & $2.40 \pm 0.76$ & $1.06 \pm 0.24$ & 11.947 & $0.000^{\star \star}$ \\
\hline
\end{tabular}

* $p<0.05$ represents statistical differences 


\begin{tabular}{|c|c|c|c|c|}
\hline \multirow[t]{2}{*}{ Indicators } & \multicolumn{2}{|c|}{ Subgroups (mean \pm standard deviation) } & \multirow[t]{2}{*}{$\mathrm{T}$} & \multirow[t]{2}{*}{$P$} \\
\hline & $\begin{array}{l}\text { Control group } \\
(\mathrm{n}=50)\end{array}$ & $\begin{array}{l}\text { Observation group } \\
(n=50)\end{array}$ & & \\
\hline Preoperative ODI (\%) & $76.84 \pm 10.74$ & $78.71 \pm 9.13$ & -0.936 & 0.352 \\
\hline $\begin{array}{l}\text { ODI (\%) } 2 \text { hours after } \\
\text { surgery }\end{array}$ & $39.91 \pm 7.99$ & $17.61 \pm 5.43$ & 16.314 & $0.000^{\star *}$ \\
\hline $\begin{array}{l}\text { ODI(\%) at hospital } \\
\text { discharge }\end{array}$ & $23.01 \pm 5.89$ & $11.17 \pm 4.93$ & 10.909 & $0.000^{\star \star *}$ \\
\hline
\end{tabular}

* $p<0.05$ represents statistical differences

\begin{tabular}{|lllll|}
\hline Indicators & \multicolumn{2}{l}{ Subgroups (mean \pm standard deviation) } & $\mathrm{T}$ & $\mathrm{p}$ \\
\cline { 2 - 5 } & $\begin{array}{l}\text { Control group } \\
(\mathrm{n}=50)\end{array}$ & $\begin{array}{l}\text { Observation group } \\
(\mathrm{n}=50)\end{array}$ & & \\
\hline Postoperative ambulation time $(\mathrm{h})$ & $5.17 \pm 0.88$ & $2.64 \pm 0.48$ & 17.831 & $0.000^{* *}$ \\
\hline $\begin{array}{l}\text { Postoperative defecation (stool) } \\
\text { time(h) }\end{array}$ & $15.83 \pm 1.33$ & $10.38 \pm 1.64$ & 18.246 & $0.000^{* *}$ \\
\hline
\end{tabular}

* $p<0.05$ represents statistical differences

\begin{tabular}{|lllll|}
\hline Indicators & \multicolumn{2}{l}{ Subgroups (mean \pm standard deviation) } & $\mathrm{t}$ & $\mathrm{p}$ \\
\cline { 2 - 5 } & $\begin{array}{l}\text { Control group } \\
(\mathrm{n}=50)\end{array}$ & $\begin{array}{l}\text { Observation group } \\
(\mathrm{n}=50)\end{array}$ & & \\
\hline Surgery time(min) & $44.46 \pm 13.77$ & $47.72 \pm 15.27$ & -1.121 & 0.265 \\
\hline $\begin{array}{l}\text { Intraoperative bone cement } \\
\text { volume (ml) }\end{array}$ & $4.55 \pm 1.55$ & $4.65 \pm 1.19$ & -0.361 & 0.719 \\
\hline $\begin{array}{l}\text { Intraoperative blood loss }(\mathrm{ml}) \\
\text { Surgery cost (yuan) }\end{array}$ & $2.40 \pm 1.28$ & $2.56 \pm 1.20$ & -0.646 & 0.520 \\
\hline
\end{tabular}

* $p<0.05$ represents statistical differences

\section{Figures}




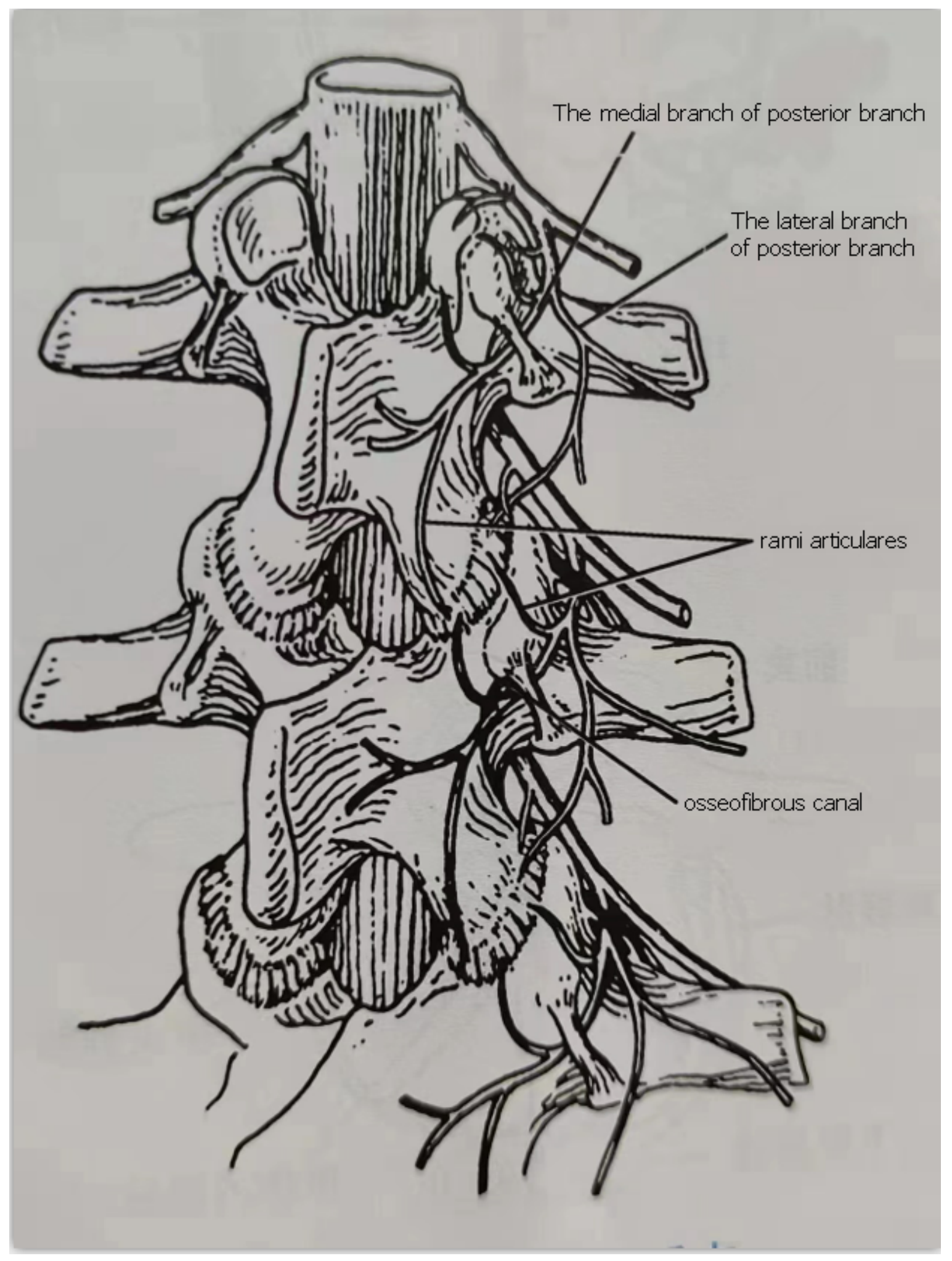

Figure 1

(Schematic Diagram) [13] 


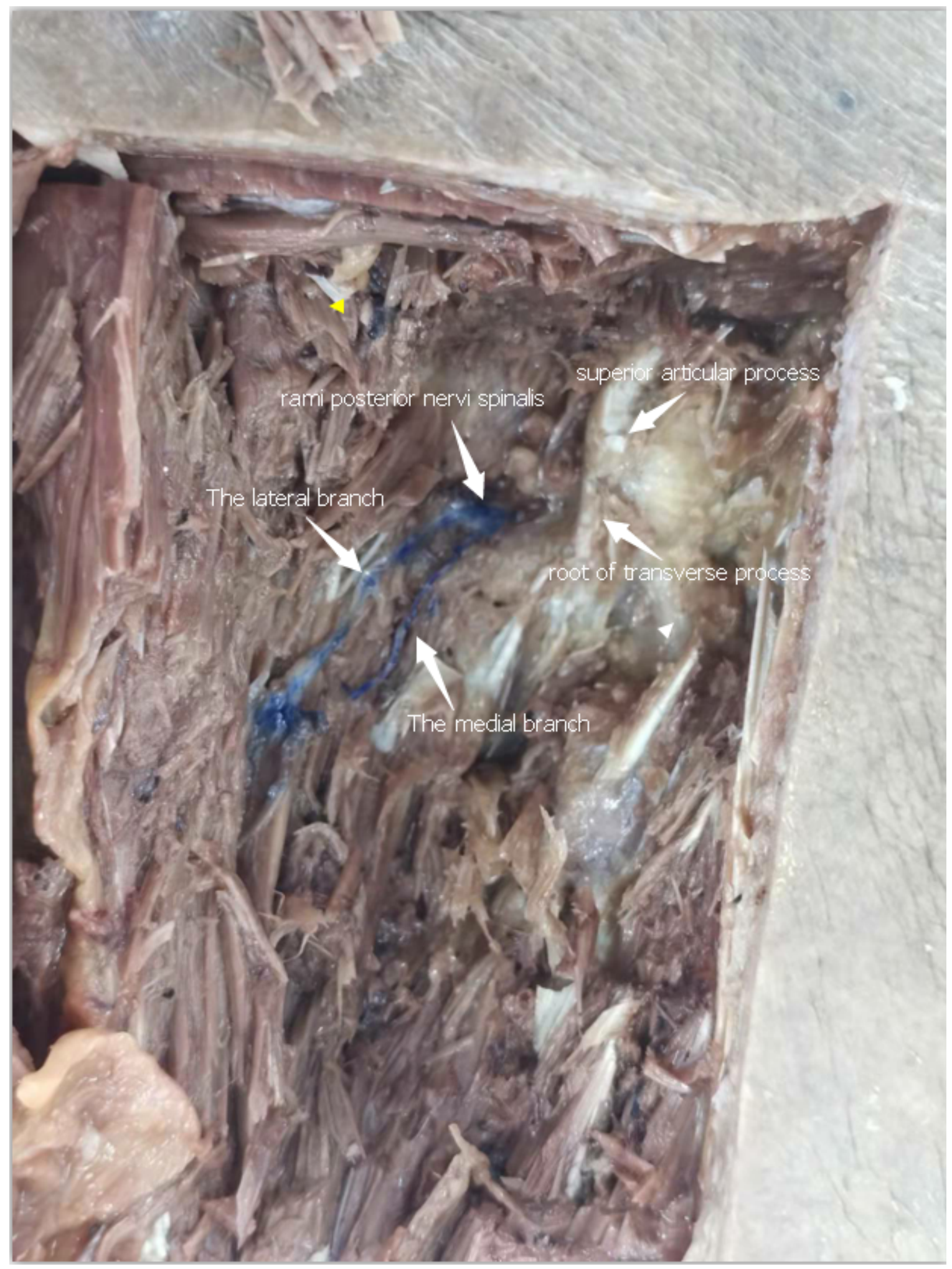

Figure 2

(shows the posterior branch of the spinal nerve emanating along the root above the transverse process and then falling into medial and lateral branches) 


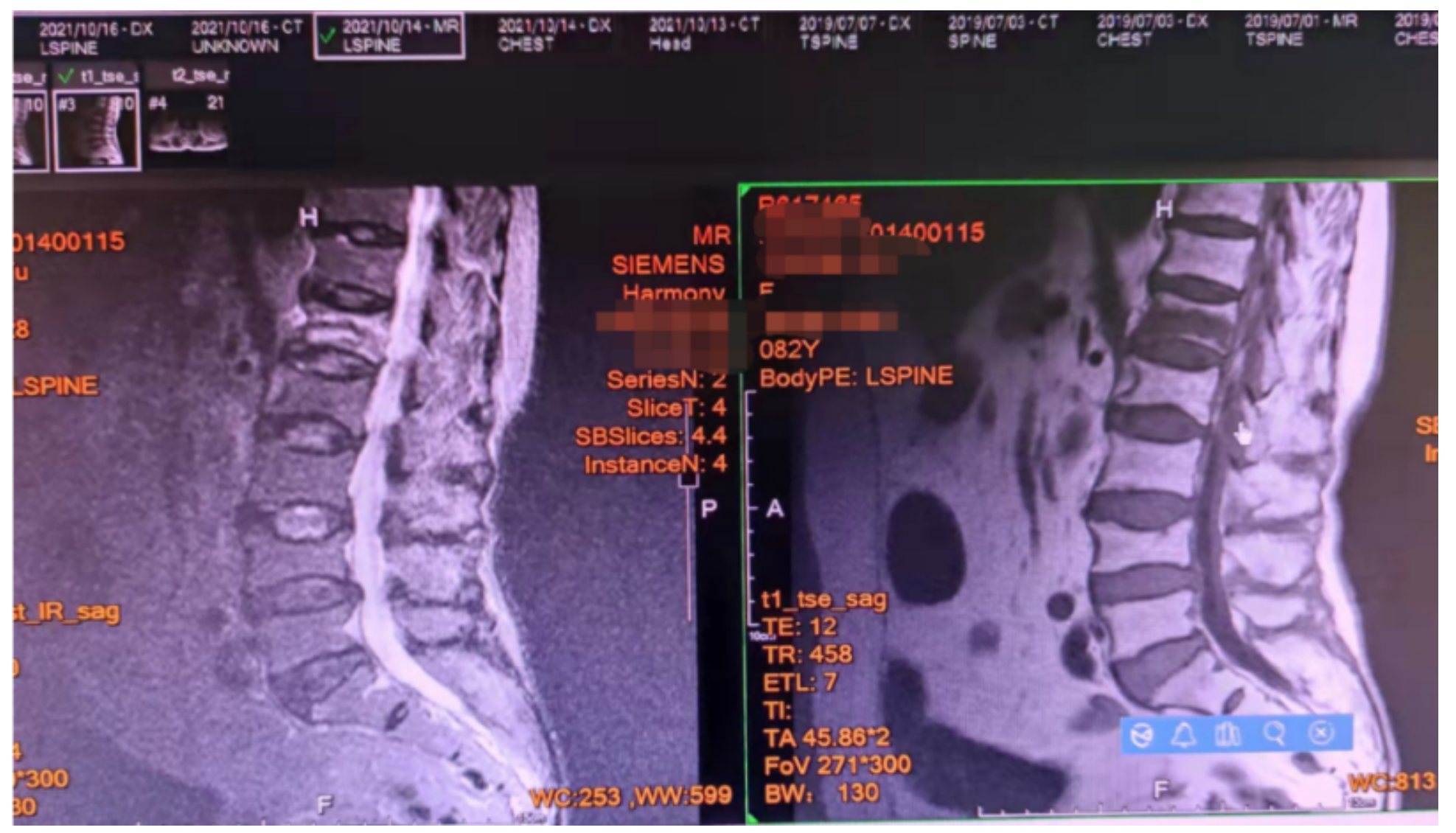

\section{Figure 3}

(MRI of lumbar spine suggests high signal in T2 image and low signal in T1 image of lumbar 1 vertebral body, and fresh fracture of lumbar 1 vertebral body) 


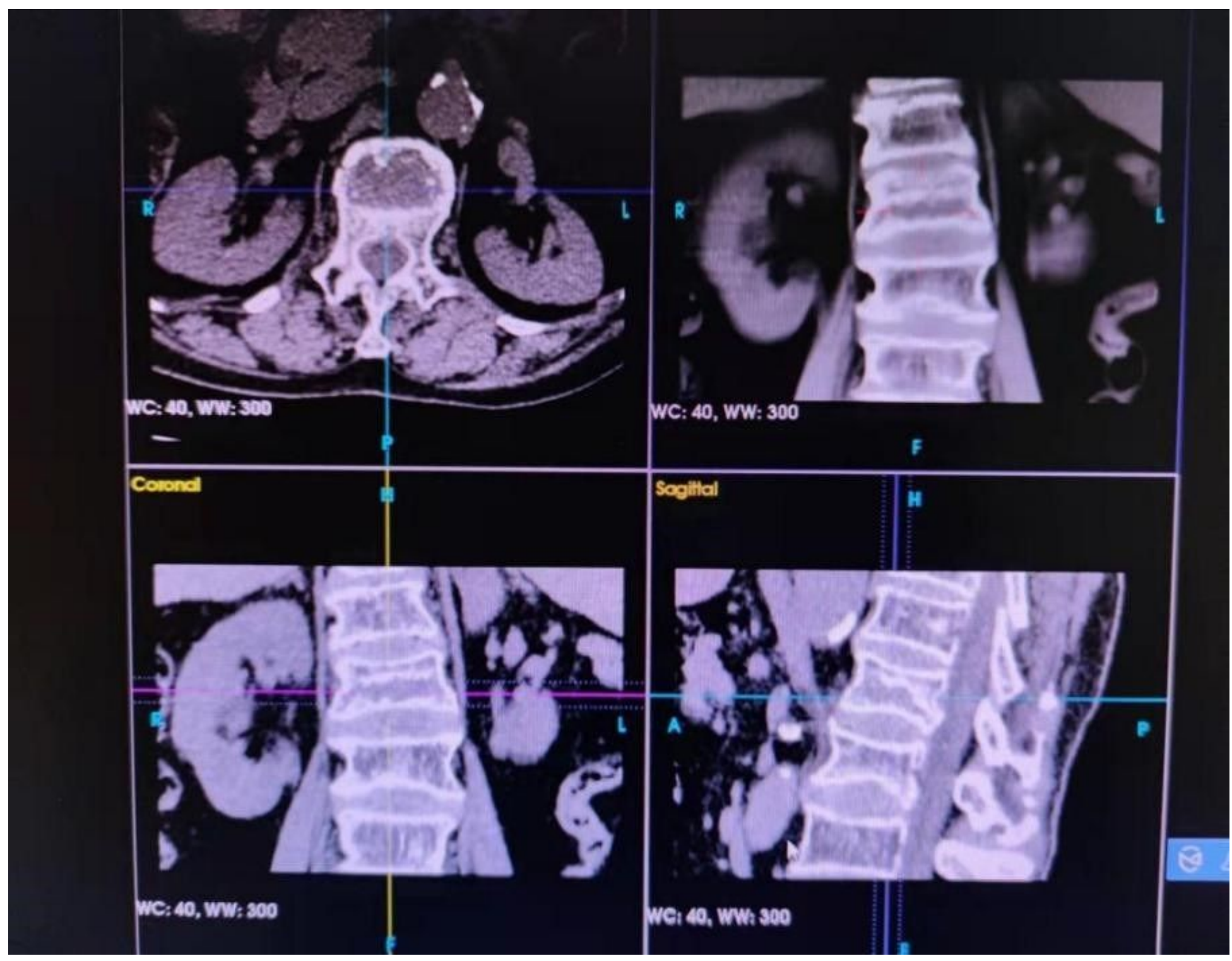

\section{Figure 4}

(CT of lumbar spine suggests intact posterior wall of lumbar 1 vertebra) 


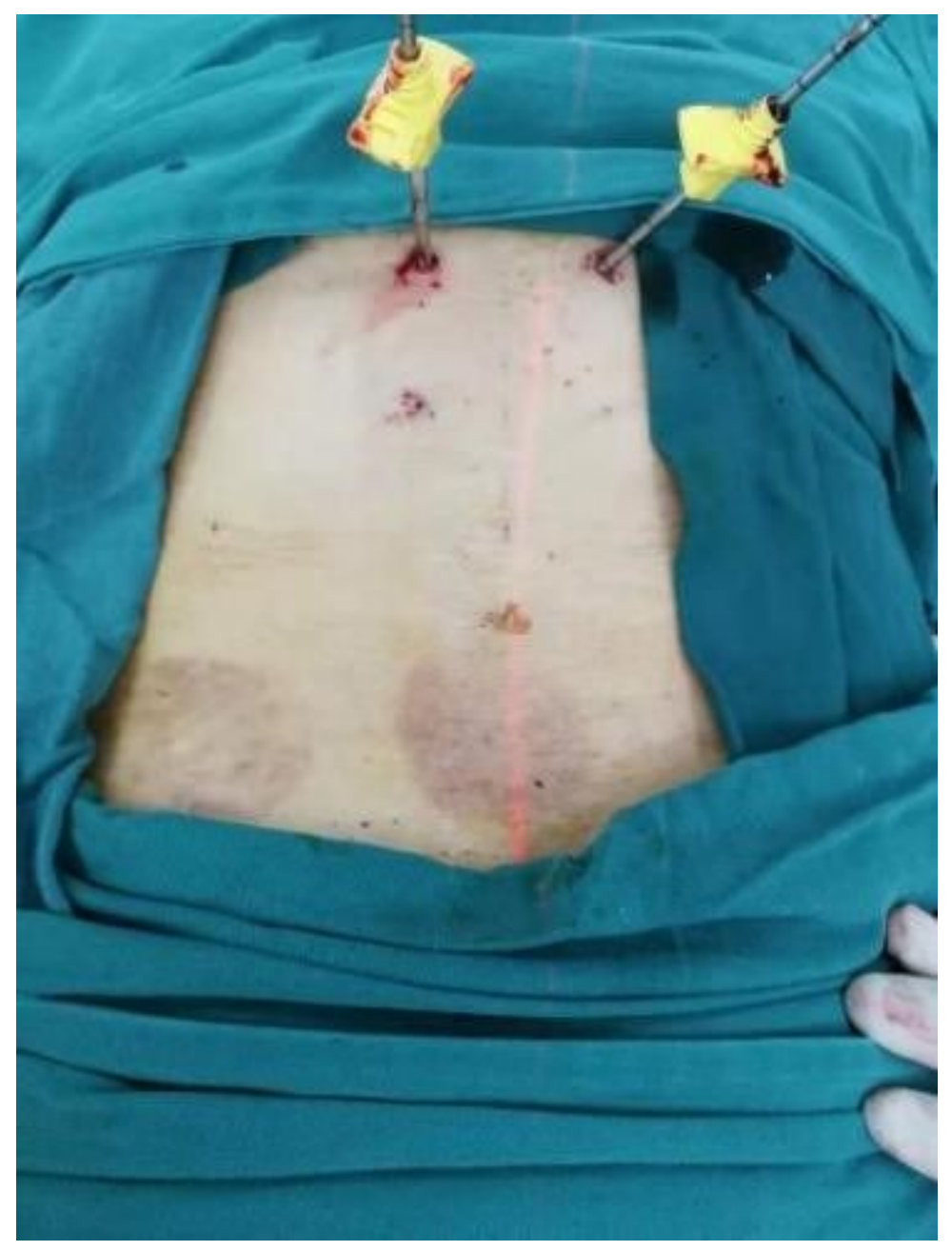

\section{Figure 5}

(After satisfactory positioning of the lumbar 1 vertebral body, bone cement was instilled along the working channel.The patient had significant radiating pain in the lumbosacral region and was treated with cupping at another hospital) 


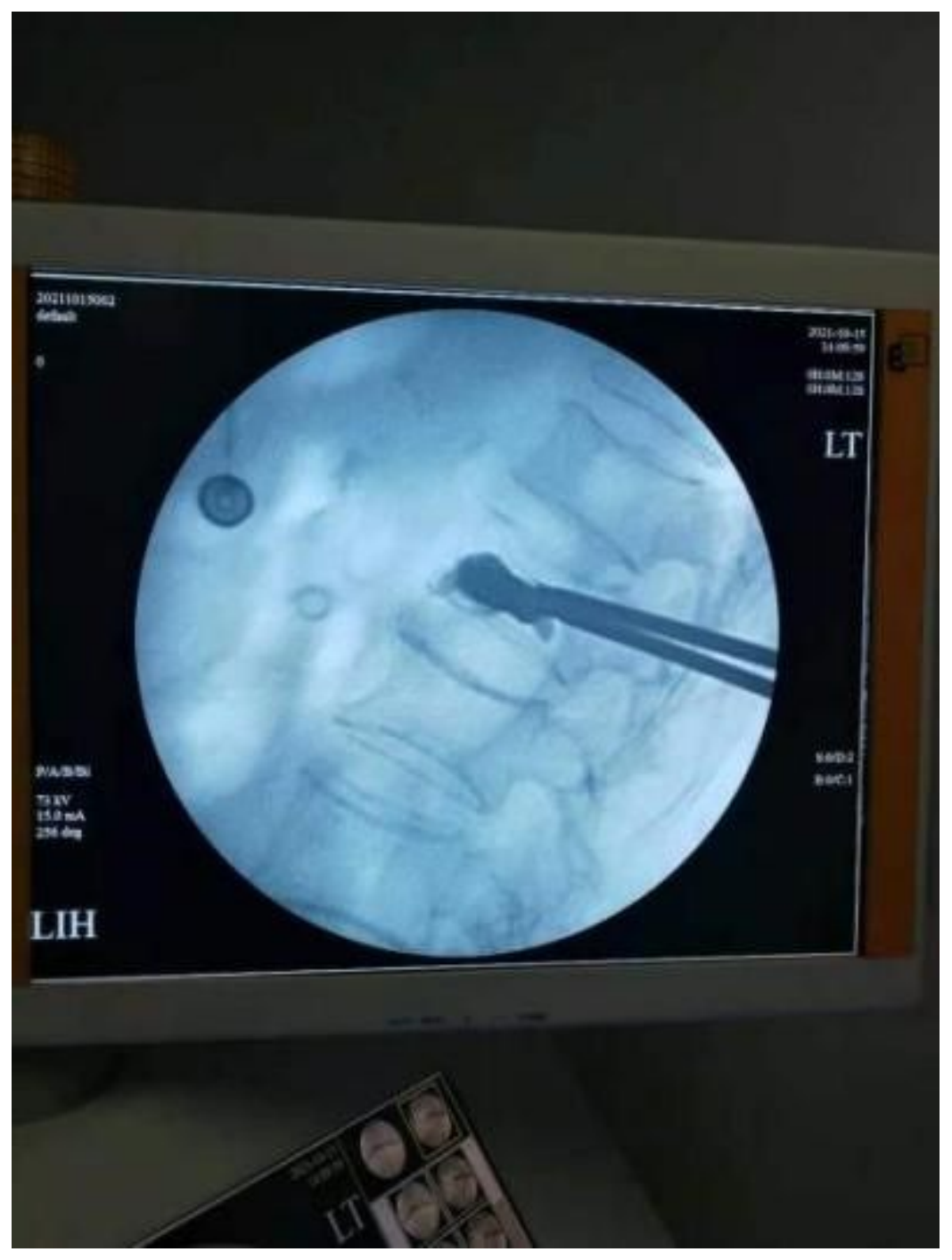

Figure 6

(The Lateral film suggests satisfactory bone cement filling) 


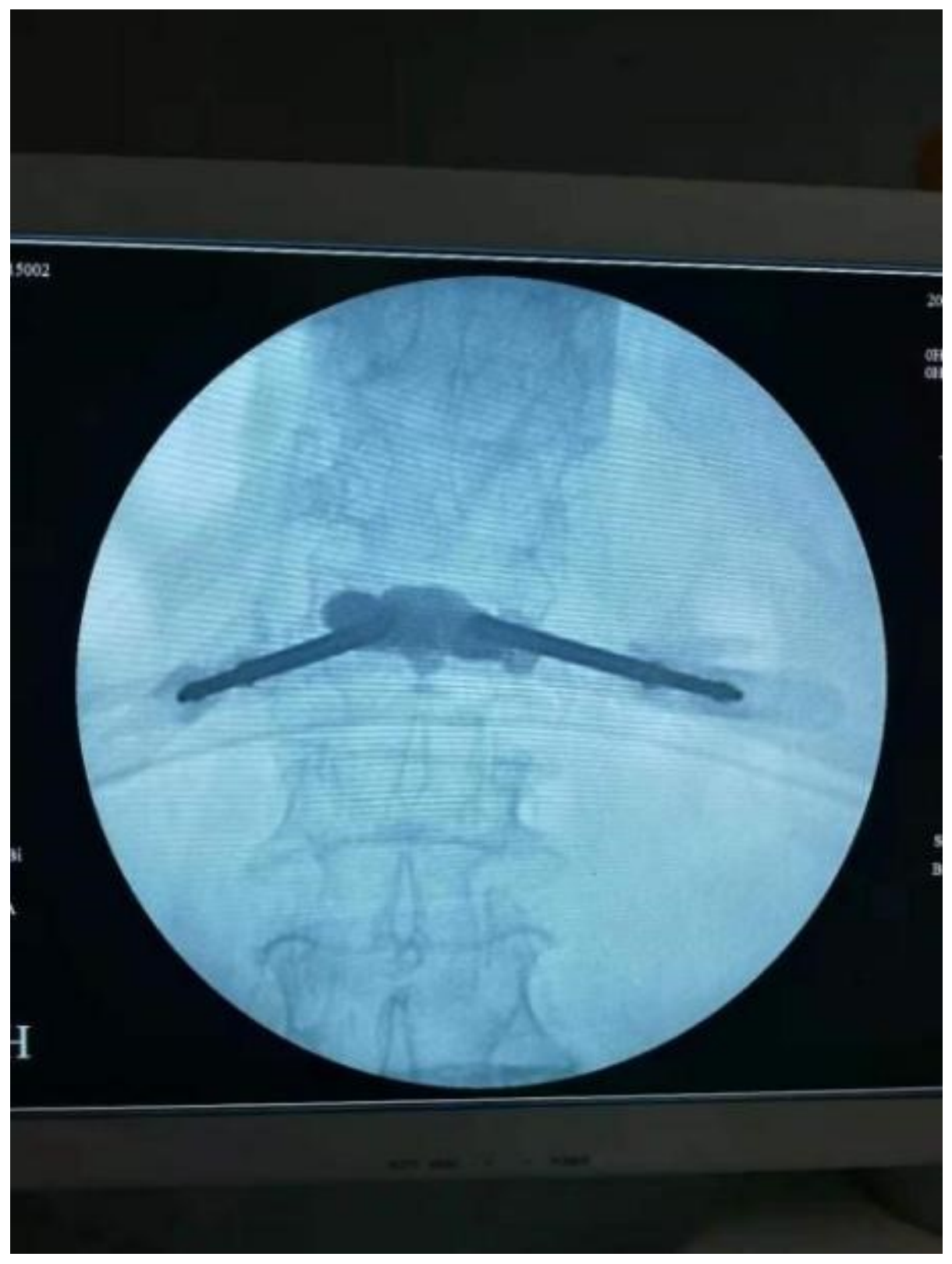

Figure 7

(The anteroposterior film suggests satisfactory bone cement filling) 


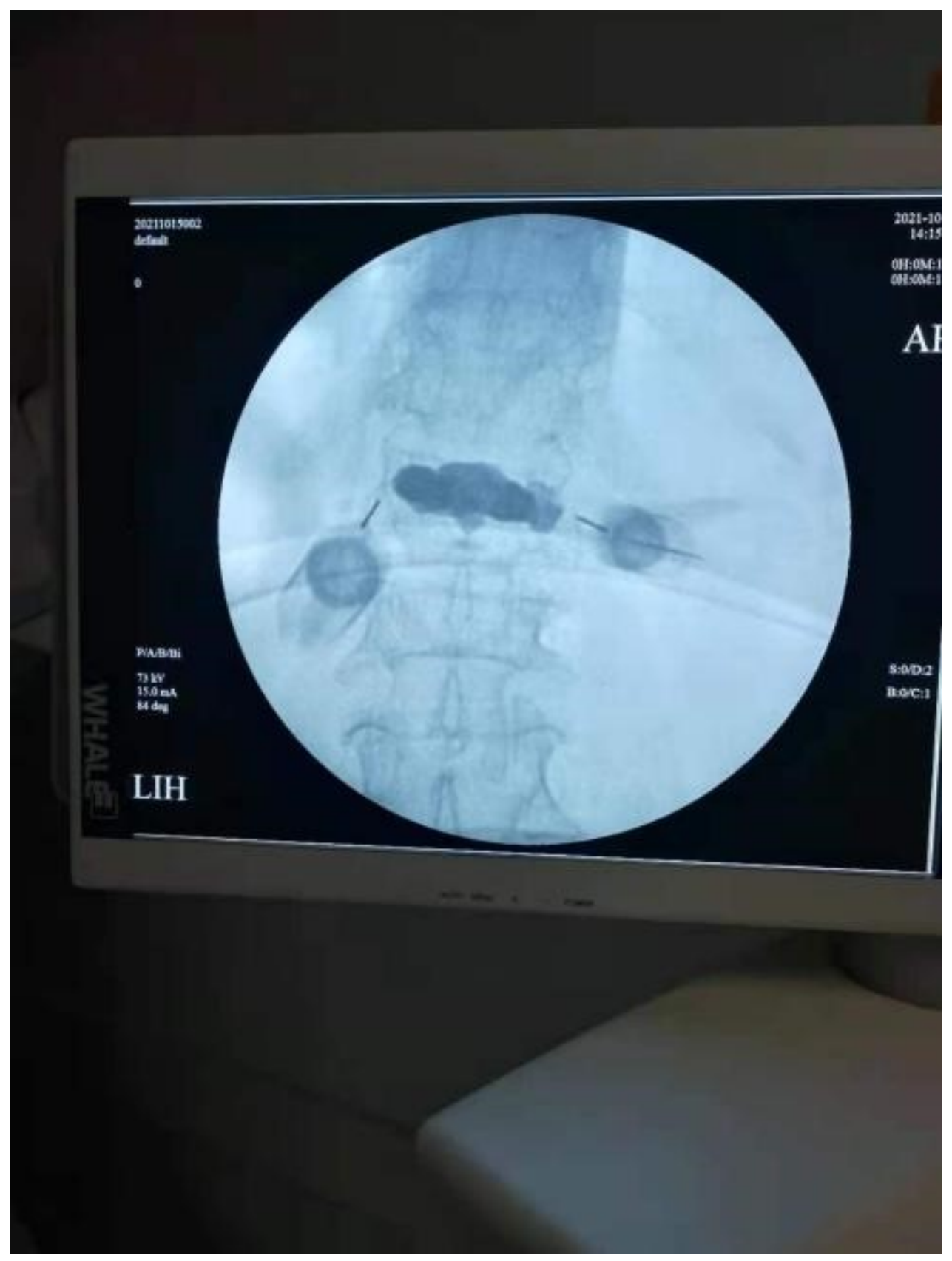

\section{Figure 8}

(ESPB treatment was completed through $5 \mathrm{ml}$ syringe at the root above the lumbar 1 transverse process bilaterally to inject $5 \mathrm{ml}$ of ropivacaine in the gap between the deep surface of the erector spinae and the transverse process, respectively) 